\title{
Design of Experiment as a powerful tool when applying Finite Element Method: a case study on prediction of hot rolling process parameters
}

\author{
Giancarlo G. Bordonaro \\ University of Applied Sciences and Arts of Southern Switzerland, Manno (Switzerland) \\ Institute for Mechanical Engineering and Materials Technology \\ giancarlo.bordonaro@supsi.ch
}

Riccardo Leardi

University of Genoa, Department of Pharmacy, Genoa (Italy)

leardi@difar.unige.it

\section{Luca Diviani}

University of Applied Sciences and Arts of Southern Switzerland, Manno (Switzerland)

Institute for Mechanical Engineering and Materials Technology

luca.diviani@supsi.ch

Filippo Berto

NTNU, Department of Engineering Design and Materials, Trondheim, (Norway)

filippo.berto@ntnu.no

ABSTRACT. The ultimate goal in hot roll pass design is to manufacture a rolled product with the required dimensional accuracy, defect free surface, and mechanical properties. The proper selection of process parameters is crucial to meet increasing requirements for desired quality and geometrical properties of rolled products. Due to the complex behavior of the metal flow at high temperatures and the severe plastic deformations in shape rolling, most efforts that have been made so far only rely upon the practical experience gained by operators. The large number of variables involved and the difficulty in investigating the process characteristics, make the use of finite element (FE) tools an effective and attractive opportunity towards a thorough understanding of the rolling process.

In this work, Design of Experiment (DOE) is proposed as a powerful and viable method for the prediction of rolling process parameters while reducing the computational effort. Nonlinear 3D FE models of the hot rolling process are developed for a large set of complex cross-section shapes and validated

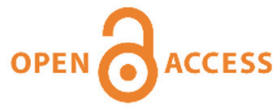

Citation: Bordonaro, G.G.., Leardi, R, Daviani, L. Berto, F., Design of Experiment as a powerful tool when applying Finite Element Method: a case study on prediction of hot rolling process parameters, Frattura ed Integrità Strutturale, 44 (2018) 1-15.

Received: 10.01 .2018

Accepted: 30.01 .2018

Published: 01.04.2018

Copyright: (C) 2018 This is an open access article under the terms of the CC-BY 4.0, which permits unrestricted use, distribution, and reproduction in any medium, provided the original author and source are credited. 
against experimental evidences provided by real plant products at each stage of the deformation sequence. Based on the accuracy of the validated FE models, DOE is applied to investigate the flat rolling process under a series of many parameters and scenarios. Effects of main roll forming variables are analyzed on material flow behavior and geometrical features of a rolled product. The selected DOE factors are the workpiece temperature, diameter size, diameter reduction (draught), and rolls angular velocity. The selected DOE responses are workpiece spread, effective stresses, contact stresses, and rolls reaction loads. Eventually, the application of Pareto optimality (a MultiCriteria Decision Making method) allows to detect an optimal combination of design factors which respect desired target requirements for the responses.

KEYWORDs. Hot rolling process; Finite Element Simulation; Design of Experiment; Multi-Criteria Decision Making; Pareto optimality.

\section{INTRODUCTION}

$\mathrm{H}$ ot rolling is a metal forming process for the production of metallic profiles with a well defined cross-section geometry. The input material consists of a preformed billet, with square or circular shape, which is preheated above the recrystallization temperature. Through compressive forces exerted by an appropriate sequence of forming rolls, the billet is plastically deformed until the final profile is obtained. Due to the complex behavior of the deformed material at high temperatures, the continuous changes of microstructural characteristics, and the high number of process variables, modern forming process design only relies on empirical approaches and practical observations. Well known empirical formulae were proposed by Wusatowski [1], Ekelund [2], The United Steel Companies [3], and Roberts [4] aimed at computing the process parameters such as rolls forces and torque, workpiece elongation and spread. However, expert designers are capable of developing specific solutions for individual roll forming problems. Although these traditional methods are still successfully used on a daily basis, the increasing demand for higher quality and custom-made products together with lower production costs, prompted industrial operators to search for numerical tools based on more scientific methods. An improved understanding of metal flow in shape rolling processes enables steel makers to improve time to market and optimize manufacturing processes. This explains why, in recent years, a growing number of academic and industrial research groups worked together to develop sophisticated numerical methods for computer-aided roll pass design. Among various approaches to simulate the material flow during the process, the Finite Element Method (FEM) is the most used to investigate rolling problems, for both two and three-dimensional analyses. Many FE models were developed for process simulations based on different formulations, rigid-viscoplastic by Bertrand et al. [5], rigid-plastic by Mori and Osakada [6], elastic-plastic by Hartley et al. [7], and by Galantuccia and Tricarico [8], for transient and steady-state analyses. Commercial FEM softwares are continually being improved for solving metal forming problems due to the increasing need for accurate predictions of metal flow and rolls groove design. Further progress was made by combining different disciplines based on expert systems, hybrid models, and stochastic algorithms aimed at rolling operations control and optimization.

Lambiase and Langella [9] developed an automatic roll pass design method capable of minimizing the number of roll pass sequences by adopting an heuristic approach for process design in combination with data from FE simulations. An expert system was designed for estimating optimal shapes of the rolls and number of passes given the size and the initial speed of the entry billet, the nominal rolls radius and the finished bar dimensions. This approach proved to increase the efficiency of the process compared with existing expert systems for bar rolling optimization. However, limitations on the estimation of power requirements and contact pressure between rolls and incoming workpiece were indicated. Abhary et al. [10] developed a knowledge-based hybrid model for improving process efficiency, resource consumption, system reliability, and product quality. The hybrid model was designed by combining stochastic, fuzzy and genetic modelling with process control, optimization as well as supply chain and maintenance management. Shashani et al. [11] designed an artificial neural network algorithm for the prediction of the thermal and structural behavior of the slab during the hot rolling process and trained by FE simulations data. Huang et al. [12] applied a parameterized approach based on artificial intelligent algorithms combined with regression analysis to predict factors such as rolling loads and roll wear and to track the relationships among parameters. Model testing and improvements were implemented through 3D FE simulations and small-scale laboratory experiments 
were implemented for model testing and improvement. Spuzic et al. [13] analyzed industrial databases of rolling pass schedules and developed statistical models along with analytical functions with the purpose of optimizing the roll pass design. Such information was used to calibrate new rolling mills profiles and reduce waste of resources. Further research was expected to be conducted to strengthen the mathematical formulation of these models through real-time applications. Lee et al. [14] proposed an analytical model for the prediction of the mean effective strain in rod rolling process. In this model, uniform deformations, proportional incremental plastic deformations along each principal axis, and linear variations of draught, spread, elongation were the major assumptions. 3D FE simulations were performed to validate the proposed analytical model with a correction factor $\eta \approx 0.9$ to take into account non-uniform deformations. Shinokura and Takai [15] investigated experimentally the spread phenomena of steel rods in four types of passes to develop a new simple formula for computer control of rod rolling process. These four types of passes included the Square-Oval, Round-Oval, SquareDiamond, and Diamond-Diamond shapes. This formula was proved to be highly accurate in the prediction of the spread by estimating only one parameter for each pass.

In this work, a methodology based on Design of Experiment techniques is provided to predict metal flow behavior of flat hot rolling process through a reduced set of 3D FE simulations. The best compromise solution among all predicted responses is obtained by applying the Pareto optimality criterion to reach desired target requirements. Flat hot rolling simulations are performed using the Hot Rolling package of the commercial software MSC Simufact Forming v. 13.1. Accuracy of simulated results is ensured by the development of $3 \mathrm{D}$ thermo-mechanical FE models for a large set of complex cross-section profiles. These models are validated with real plant products at each stage of the deformation sequence.

\section{Finite ELEMENT MODELING}

3 D rolling models are developed for the simulation at each deformation stage of the hot rolling process sequence for a low-carbon steel using the commercial FE software package MSC Simufact Forming v. 13.1. Since in metal forming operations, elastic strains contribution is negligible with respect to nonlinear plastic strains, a rigid-plastic approach can be reasonably adopted for the analysis [16]. According to the work of Kobayashi et al. [17] and Zienkiewicz [18], thermal and mechanical problems need to be solved simultaneously. The coupling occurs when large plastic deformations and contact pressure generate heat transfer which is a source of changes in the mechanical problem. Updated Lagrangian Formulation through the use of the software is selected to solve the coupled thermo-mechanical problem according to Pietrzyk and Lenard [16,19]. The temperature distribution and velocity field, strain rate, strain and stress fields are calculated in the deformed zone.

\section{THERMAL BOUNDARY CONDITIONS}

he thermal boundary value problem is described by the solution of the heat diffusion equation [20,21] such that both transient and steady-state conditions satisfy thermal boundary conditions. Heat transfer phenomena are due to various sources. One source of heat is generated by friction on rolls-workpiece contact regions and workpiece plastic deformation, whilst heat loss sources are induced by radiation and convection to the environment from free surfaces, conduction transfer to the rolls, and temperature changes during metallurgical transformations. Additional heat loss sources may be due to air or water cooling. Thermal boundary conditions are assigned by setting mass density, thermal conductivity, and specific heat capacity. The coefficient of thermal expansion and emissivity are set respectively equal to $1.17 \times 10^{-5} / \mathrm{K}$ and $0.8[19]$.

\section{MECHANICAL BOUNDARY CONDITIONS}

he mechanical boundary value problem is governed by equilibrium equations, von Mises yield criterion, flow rule, and constitutive equations. Boundary conditions are assigned to rolls velocity and surface tractions on the rollsworkpiece contact interface. Contact properties are defined as a stick-slip numerical model based on the Coulomb friction model:

$$
\begin{cases}\sigma_{\mathrm{t}}<\mu \cdot \sigma_{\mathrm{n}} & \text { Stick condition } \\ \sigma_{\mathrm{t}}=-\mu \cdot \sigma_{\mathrm{n}} \mathrm{t} & \text { Slip condition }\end{cases}
$$


where

- $\sigma_{\mathrm{n}}=$ normal stress

- $\sigma_{\mathrm{t}}=$ tangential friction stress

- $\mu=$ friction coefficient

- $\mathbf{t}=$ tangential vector in the direction of the relative velocity $\left(\mathrm{t}=\frac{\nu_{r}}{\left|\nu_{r}\right|}\right)$

- $\quad \nu_{\mathrm{r}}=$ relative sliding velocity

The friction coefficient $\mu$ is assumed constant and equal to 0.4. This conservative value represents the worst case for hot rolling processes where the friction coefficient normally ranges between 0.3 and 0.4 . It accounts for large reductions of the cross-sectional area at each deformation step and ensures consistency between the workpiece feed rate and rolls angular velocity while preventing from excessive slippage. The influence of temperature on the friction coefficient is insignificant for lubricated surfaces [22], thus explaining the assumed constant value. The workpiece feed rate is imposed by applying an angular velocity to the rolls.

\section{MATERIAL MODEL}

he constitutive behavior of the material in hot rolling processes above the recrystallization temperatures $\left(700^{\circ} \mathrm{C}-\right.$ $1200^{\circ} \mathrm{C}$ ) depends on the type of material (low/high Carbon, alloys), strain rate, and working temperature. According to Pietrzyk and Lenard [19, 16], the rigid-plastic flow formulation of the material based on the Levy-Mises model [19] is more suitable for large nonlinear plastic deformations, as found in hot rolling processes. This plasticity law assumes that the effects of strain rate and temperature on material properties is much larger than the work hardening and the elastic deformations, in accordance with the incompressible flow hypothesis.

Pietrzyk and Lenard [19] reported that Shida [23] in 1969 developed empirical equations for low, medium, high carbon steels. These plasticity models describe the metal flow strength $(\sigma)$ at high temperatures $(\mathrm{T})$, as a function of strain rate $(\dot{\varepsilon})$, strain $(\varepsilon)$, and carbon content $(\% \mathrm{C})$, in austenitic, ferritic, and two-phase regions [19]. The mathematical formulation of Shida's empirical relations (eq. 1) is as follows:

$$
\sigma=\sigma_{\mathrm{f}} \mathrm{f}\left(\frac{\dot{\varepsilon}}{10}\right)^{\mathrm{m}}\left(\frac{\mathrm{kg}}{\mathrm{mm}^{2}}\right)
$$

where

- for $\overline{\mathrm{T}} \geq 0.95 \frac{\mathrm{C}+0.41}{\mathrm{C}+0.32}$

$$
\begin{aligned}
& \sigma_{\mathrm{f}}=0.28 \mathrm{e}^{\left(\frac{5}{\left.\overline{\bar{T}}-\frac{0.01}{\mathrm{C}+0.05}\right)}\right.} \\
& \mathrm{m}=(-0.019 \mathrm{C}+0.126) \overline{\mathrm{T}}+(0.075 \mathrm{C}-0.05)
\end{aligned}
$$

- for $\overline{\mathrm{T}} \leq 0.95 \frac{\mathrm{C}+0.41}{\mathrm{C}+0.32}$

$$
\begin{aligned}
& \sigma_{f}=0.28 q(C, \bar{T}) e^{\left(\frac{C+0.32}{0.19(C+0.41)}-\frac{0.01}{C+0.05}\right)} \\
& q(C, \bar{T})=30(C+0.9)\left[\bar{T}-0.95 \frac{C+0.49}{C+0.42}\right]^{2}+\frac{C+0.06}{C+0.09} \\
& m=(0.081 C-0.154) \bar{T}-0.019 C+0.207+\frac{0.027}{C+0.32}
\end{aligned}
$$


Other parameters are defined as follows

$$
\begin{aligned}
& \mathrm{f}=1.3\left(\frac{\varepsilon}{0.2}\right)^{\mathrm{n}}-0.3\left(\frac{\varepsilon}{0.2}\right) \\
& \mathrm{n}=0.41-0.07 \mathrm{C} \\
& \overline{\mathrm{T}}=\frac{\mathrm{T}+273.15}{1000} \\
& \mathrm{~T}=\text { temperature in }{ }^{\circ} \mathrm{C}, 700^{\circ} \mathrm{C}<\mathrm{T}<1200^{\circ} \mathrm{C} \\
& \mathrm{C}=\text { carbon content in weight percent, } \mathrm{C}<1.2 \% \\
& \dot{\varepsilon}=\text { strain rate, } 0.1<\dot{\varepsilon}<100 \mathrm{~s}^{-1} \\
& \varepsilon=\text { strain }<70 \%
\end{aligned}
$$

Shida's material formulation allows to define thermal properties as a function of temperature $\overline{\mathrm{T}}$ for low-carbon steels, as follows:

- thermal conductivity $(\mathrm{k})$ :

$$
\mathrm{k}=23.16+51.96 \cdot \mathrm{e}^{-2.03 \cdot \overline{\mathrm{T}}}\left(\frac{\mathrm{W}}{\mathrm{m}}\right)
$$

- $\quad$ material density $(\varrho)$ :

$$
\varrho=\frac{7850}{\left(1+0.004 \cdot \overline{\mathrm{T}}^{2}\right)^{3}}\left(\frac{\mathrm{kg}}{\mathrm{m}^{3}}\right)
$$

- $\quad$ specific heat capacity $\left(C_{\mathrm{p}}\right)$ :

$$
\begin{aligned}
& \mathrm{C}_{\mathrm{p}}=689.2+46.2 \cdot \mathrm{e}^{3.78 \cdot \overline{\mathrm{T}}}, \mathrm{T}<700^{\circ} \mathrm{C} \\
& \mathrm{C}_{\mathrm{p}}=207.9+294.4 \cdot \mathrm{e}^{1.41 \cdot \overline{\mathrm{T}}}, \mathrm{T} \geq 700^{\circ} \mathrm{C}\left(\frac{\mathrm{J}}{\mathrm{kgK}}\right)
\end{aligned}
$$

Shida's equation is applied to compute flow curves for the low-carbon steel S235JR $(0.17 \% \mathrm{C})$ at different working temperatures in the range of $800^{\circ} \mathrm{C} \leq \mathrm{T} \leq 1200^{\circ} \mathrm{C}$ and at different strain rates in the range of $0.1 \leq \dot{\varepsilon} \leq 10 \frac{1}{s}$. These flow curves are used in this study as an input to the material module of the software MSC Simufact Forming. It is assumed a temperature independent modulus of elasticity of $210 \mathrm{GPa}$ and Poisson's ratio of 0.3 .

\section{FEM RESULTS AND VALIDATION}

3

D FE models of multi-pass hot rolling processes are developed for a total of six profiles with a complex cross-section. Simulations are carried out with the commercial software Simufact Forming. This software is a sophisticated simulation tool which considers the triaxiality of the stress state with dedicated meshing and remeshing techniques for metal forming processes. To achieve the required precision in the simulations an adequately fine mesh is required, which must be carried out due to the three-dimensional stress state with continuous elements (full 3D elements). Due to the large plastic deformations the simulation mesh requires continuous remeshing to prevent the simulation from failing due to extremely distorted elements. Simufact Forming provides for this purpose a powerful algorithm that execute an automatic hexahedral remeshing when it is required. Thermo-mechanical boundary conditions and material model flow curves are implemented based on assumptions described in the previous sections. Process parameters at each deformation stand are defined from real plant data: billet cross-section geometry, workpiece temperature, rolls angular velocity, rolling mill set-up equipment either idle or motorized, horizontal or vertical axes. Table 1 shows ranges for the workpiece temperatures and rolls angular velocities performed in the multi-pass rolling. The entry billet diameter is also shown in the same table for each analyzed profile type. 


\begin{tabular}{cccc}
\hline Profile type & Entry billet & Temperature & Rolls RPM \\
Diameter $(\mathrm{mm})$ & Range $\left({ }^{\circ} \mathrm{C}\right)$ & Range \\
$\mathrm{T}$ & 48 & $1000-1200$ & $10-30$ \\
Hinge & 60 & $1000-1200$ & $5-18$ \\
Rail & 38 & $1000-1200$ & $12.5-21$ \\
Handrail & 46 & $1000-1200$ & $7.4-16.7$ \\
$\mathrm{H}$ & 24 & $1000-1200$ & $19-48.7$ \\
$\mathrm{Z}$ & 42 & $1000-1200$ & $7.3-38.5$ \\
\hline
\end{tabular}

Table 1: Rolling process parameters.

A total of twenty-four simulations are implemented according to the real plant layout which consists of a continuous sequence of four passes for the whole deformation of each profile. Each deformation step is modeled and computed individually such that results from the first simulated stand are supplied to the second stand, and so on up to the last pass. All stands are simulated successfully with a satisfactory shape agreement between real and simulated profiles. Due to confidential disclosure agreements on proprietary information of the funding company only the last pass of the whole multipass process is shown for each simulated profile. Results from these simulations are depicted in Figures 1 to 6. Each Figure shows the geometry obtained in the rolling mill facility at the exit of the last deformation stand and thermal and stress contours of the simulations at the end of the same stand.

A complete mapped validation of numerical results with experimental data of thermal and stress fields across the section of the real parts is not available, but simulated results show that boundary conditions are respected. The high level of accuracy reached by the developed models, is also demonstrated by the good shape agreement when real and simulated profiles are superimposed. A well-defined formulation of the material model and process input parameters allow to simulate accurately metal flow behavior at different temperatures, mill angular velocities, and draughts.

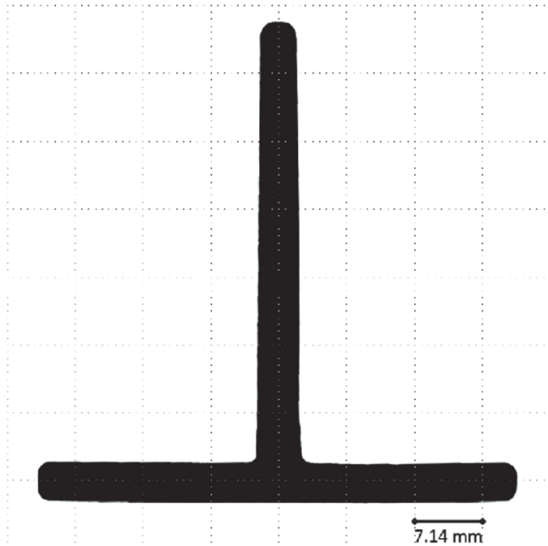

(a) Cross-section of the real rolled product.

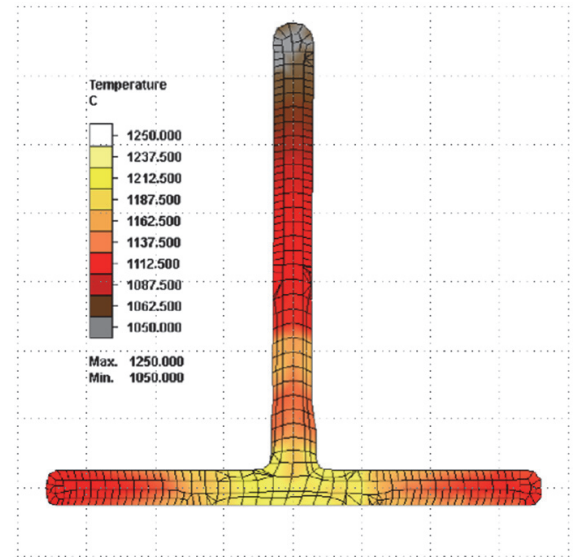

(b) Cross-section of the simulated profile: thermal contour.

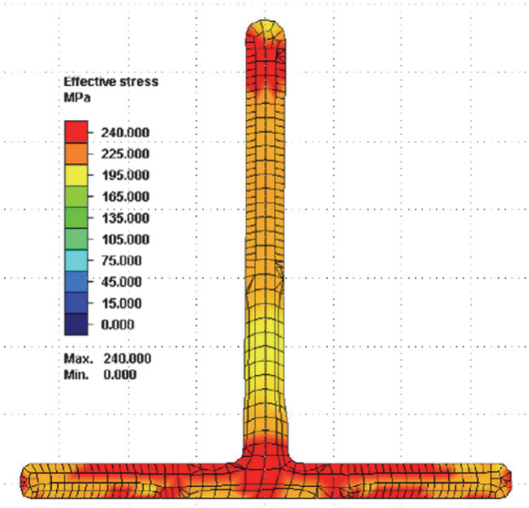

(c) Cross-section of the simulated profile: stress contour.

Figure 1: T profile geometry: comparison of real sample vs. simulated results.

\section{EXPERIMENTAL DESIGN}

$\mathrm{T}$

he developed nonlinear 3D FE models are demonstrated to accurately analyze the metal flow behavior of hot rolling strips under a series of different parameters and scenarios. These results are obtained by selecting the correct combination of process parameters thanks to the practical experience of industrial operators. Design of Experiments applied to Finite Element Method is proposed as a viable approach for the prediction of these parameters in such complicated thermo-mechanical problems. As a case study, DOE is applied to flat hot rolling process FE simulations. Figure 7 shows a sample of the 3D FE models developed for the analysis. Models are built by exploiting planes of symmetry to reduce the analysis run time and memory required. 


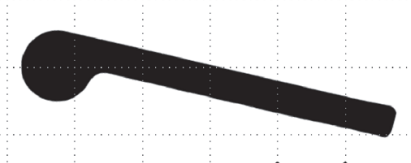

$\underset{16 \mathrm{~mm}}{\longrightarrow}$ (a) Cross-section of the real rolled product.

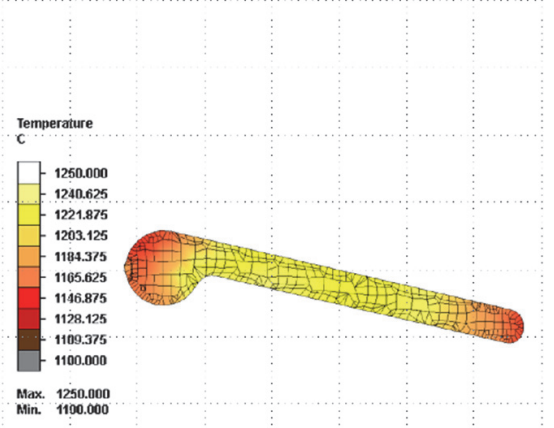

(b) Cross-section of the simulated profile: thermal contour.

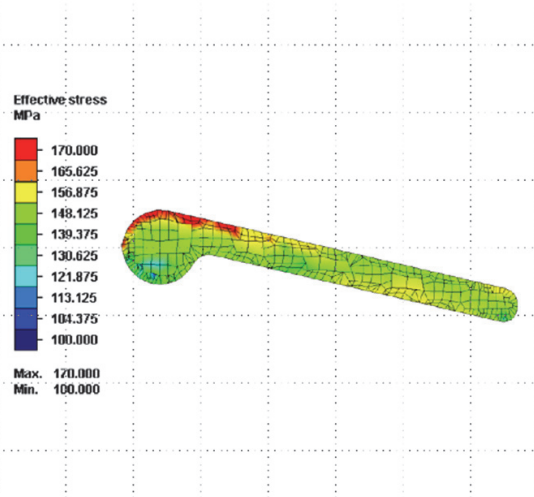

(c) Cross-section of the simulated profile: stress contour.

Figure 2: Hinge profile geometry: comparison of real sample vs. simulated results.

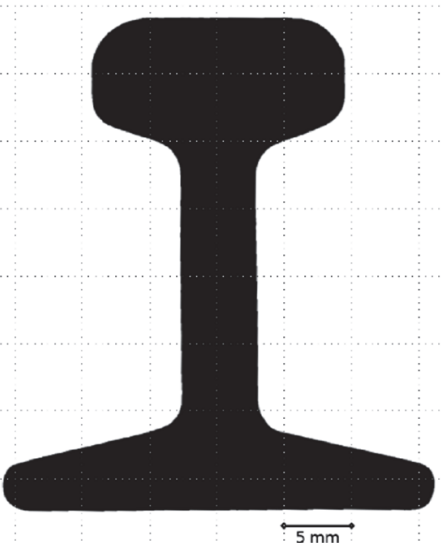

(a) Cross-section of the real rolled product.

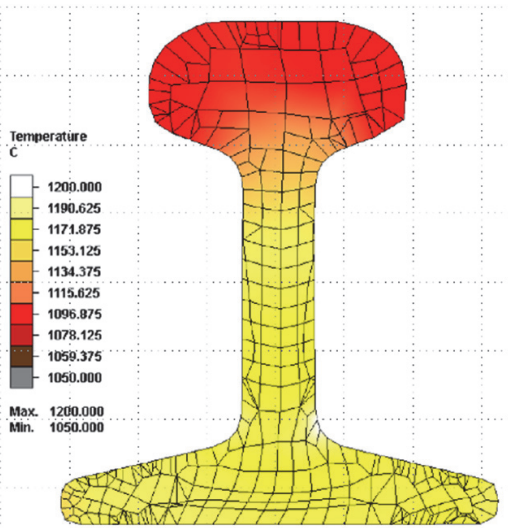

(b) Cross-section of the simulated profile: thermal contour.

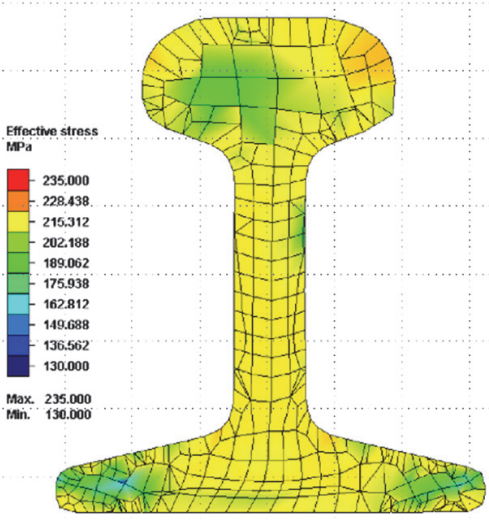

(c) Cross-section of the simulated profile: stress contour.

Figure 3: Rail profile geometry: comparison of real sample vs. simulated results.

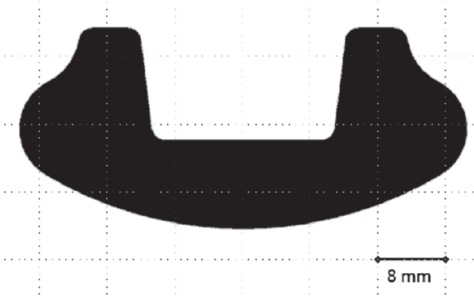

(a) Cross-section of the real rolled product.

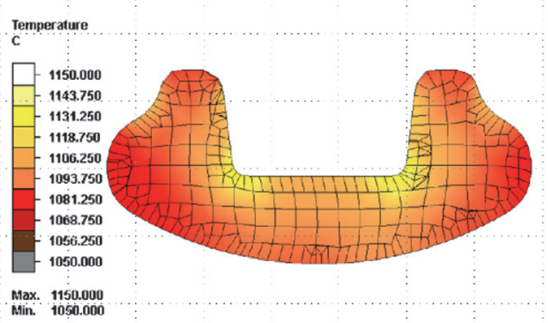

(b) Cross-section of the simulated profile: thermal contour.

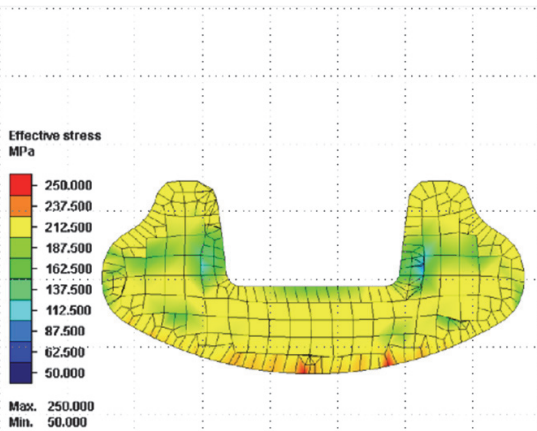

(c) Cross-section of the simulated profile: stress contour.

Figure 4: Handrail profile geometry: comparison of real sample vs. simulated results. 


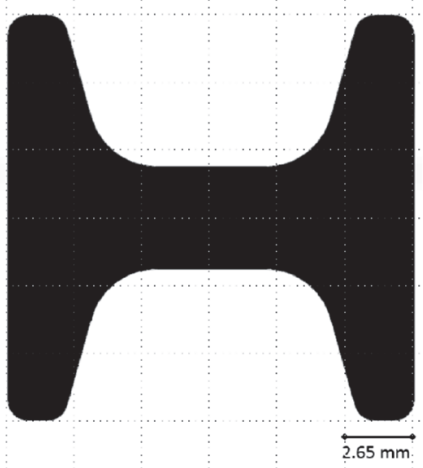

(a) Cross-section of the real rolled product.

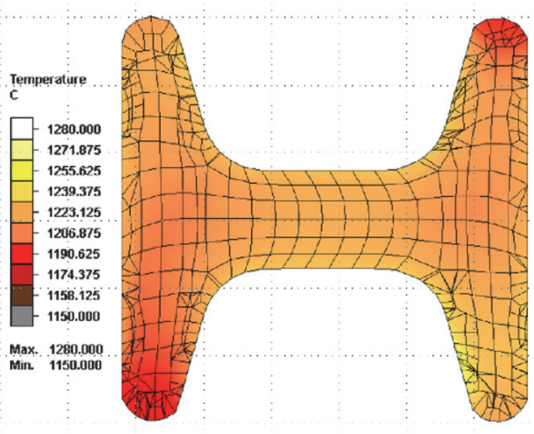

(b) Cross-section of the simulated profile: thermal contour.

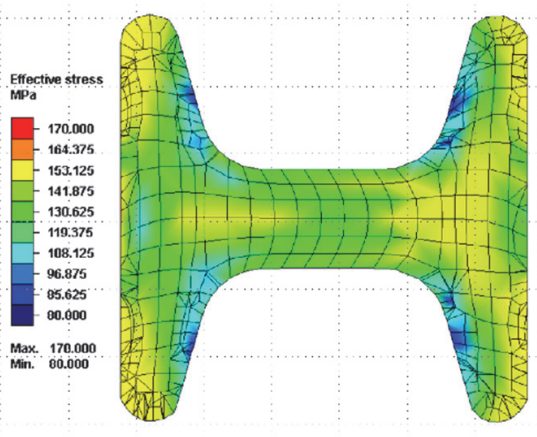

(c) Cross-section of the simulated profile: stress contour.

Figure 5: H profile geometry: comparison of real sample vs. simulated results.

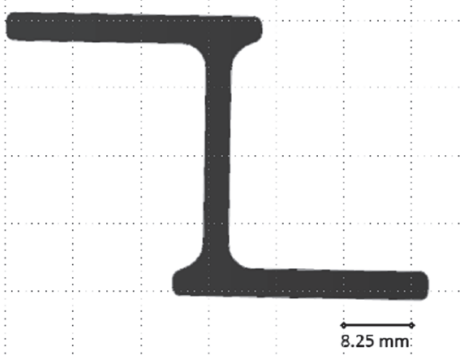

(a) Cross-section of the real rolled product.

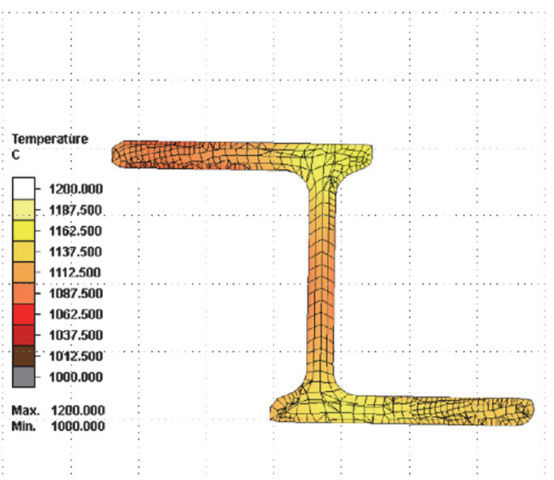

(b) Cross-section of the simulated profile: thermal contour.

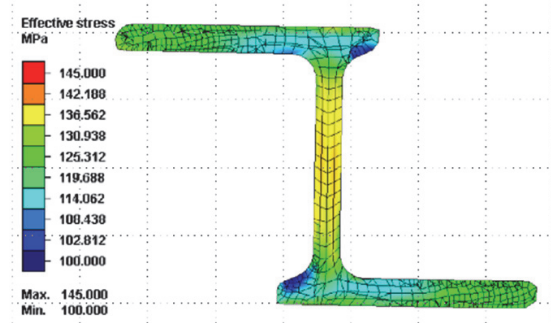

(c) Cross-section of the simulated profile: stress contour.

Figure 6: Z profile geometry: comparison of real sample vs. simulated results.

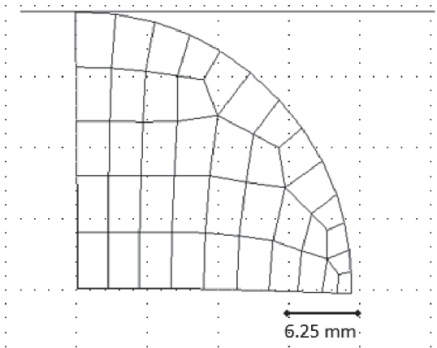

(a) Rolling initial condition before deformation.

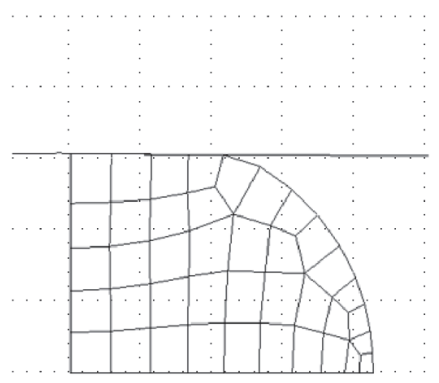

(b) Rolling at steady-state after deformation.

Figure 7: Sample of the 3D finite element models developed for the flat hot rolling simulations.

The material behavior is modeled using a rigid-plastic flow formulation based on the Levy-Mises model [17] as described above, rolls are assumed to be rigid, and thermo-mechanical boundary conditions are implemented in the model. Contact pressure in the rolls-workpiece interface is defined according to the described Coulomb friction model with a constant friction coefficient $\mu=0.4$. 


\section{STEPS FOR DESIGN OF COMPUTER EXPERIMENT}

he goal of this analysis is to determine effects and possible interaction effects of a set of different process variables on significant process responses [24]. Based on experience from rolls designers, four factors are thought to affect the rolling product characteristics (billet temperature, billet size, rolls angular velocity, draught). The mathematical model, containing one constant, four linear terms, six interactions and four quadratic terms, is the following:

$$
\begin{aligned}
\mathrm{Y}= & \mathrm{b}_{0}+\mathrm{b}_{1} \mathrm{X}_{1}+\mathrm{b}_{2} \mathrm{X}_{2}+\mathrm{b}_{3} \mathrm{X}_{3}+\mathrm{b}_{4} \mathrm{X}_{4}+\mathrm{b}_{12} \mathrm{X}_{1} \mathrm{X}_{2}+\mathrm{b}_{13} \mathrm{X}_{1} \mathrm{X}_{3}+\mathrm{b}_{14} \mathrm{X}_{1} \mathrm{X}_{4}+ \\
& +\mathrm{b}_{23} \mathrm{X}_{2} \mathrm{X}_{3}+\mathrm{b}_{24} \mathrm{X}_{2} \mathrm{X}_{4}+\mathrm{b}_{34} \mathrm{X}_{3} \mathrm{X}_{4}+\mathrm{b}_{1}{ }^{2} \mathrm{X}_{1}{ }^{2}+\mathrm{b}_{2}{ }^{2} \mathrm{X}_{2}{ }^{2}+\mathrm{b}_{3}{ }^{2} \mathrm{X}_{3}{ }^{2}+\mathrm{b}_{4}{ }^{2} \mathrm{X}_{4}{ }^{2}
\end{aligned}
$$

where terms $\mathrm{X}_{\mathrm{i}}$ are the process variables:

- $\mathrm{X}_{1}$ : workpiece temperature $\left[{ }^{\circ} \mathrm{C}\right]$

- $\mathrm{X}_{2}$ : rolls angular velocity $[\mathrm{RPM}]$

- $\mathrm{X}_{3}$ : workpiece diameter [mm]

- $\mathrm{X}_{4}$ : draught in terms of diameter reduction [\%]

In this design each variable has three levels, respectively coded as $-1,0$ and +1 :

- $\mathrm{X}_{1}: 800,1000,1200\left[{ }^{\circ} \mathrm{C}\right]$

- $\mathrm{X}_{2}: 5,17.5,30$ [RPM]

- $\mathrm{X}_{3}: 20,40,60[\mathrm{~mm}]$

- $\mathrm{X}_{4}: 20 \%, 40 \%, 60 \%[\%]$

The following responses, measured after reaching a steady-state condition, are taken into account, with $Y_{1}$ and $Y_{2}$ to be maximized and $\mathrm{Y}_{3}$ and $\mathrm{Y}_{4}$ to be minimized:

- $\mathrm{Y}_{1}$ : spread $[\mathrm{mm}]$

- $\mathrm{Y}_{2}$ : effective stress in the contact region $[\mathrm{MPa}]$

- $\mathrm{Y}_{3}$ : effective stress in the non-contact region $[\mathrm{mm}]$

- $\mathrm{Y}_{4}$ : rolls reaction force (average) $[\mathrm{kN}]$

A standard experimental design such as the Central Composite Design with just one center point would require a total of 25 experiments (i.e., $2^{4}+2 \cdot 4+1$ ). In order to further reduce the experimental effort, a D-Optimal design has instead been performed. This statistical tool allows to identify, among all the possible experiments (in our case 81, i.e., $3^{4}$ ), the subset leading to the best possible compromise between experimental effort and quality of information by maximizing the normalized determinant of the information matrix $\left(\operatorname{det}\left(\mathbf{X}^{\prime} \mathbf{X}\right\} / \mathrm{n}^{\mathrm{p}}\right)$, where $\mathbf{X}$ is the model matrix, $\mathrm{n}$ is the number of experiments and $\mathrm{p}$ is the number of parameters in the model. Figure 8 shows the variation of the normalized determinant versus the number of experiments. The solution with 22 experiments has been selected.

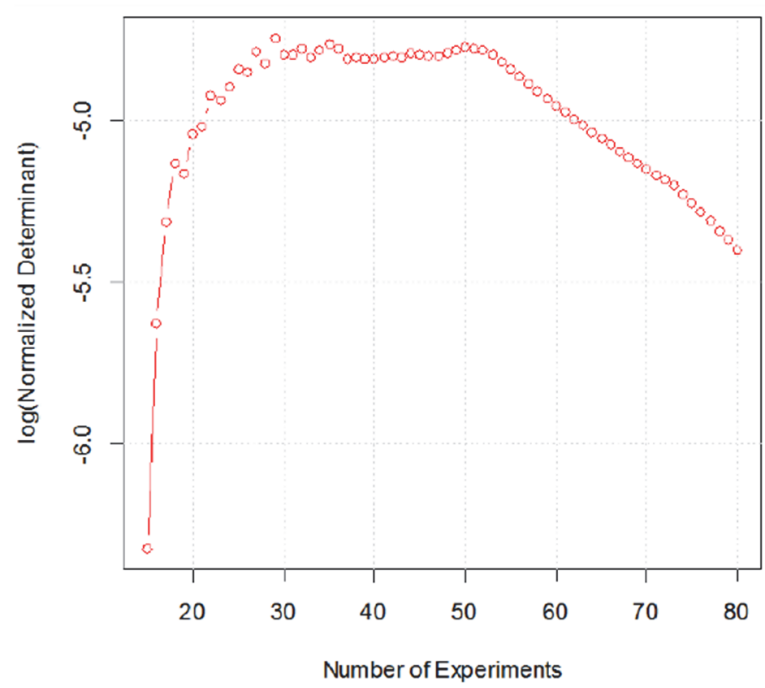

Figure 8: Normalized determinant of the information matrix is represented versus the number of experiments. 
3D FE models are developed and simulations are performed according to the experimental matrix in Table 2. The loadings plot of the Principal Component Analysis (PCA) performed on the responses shows two pairs of correlated responses. Each pair consists of one response to be maximized and the other to be minimized as shown in Figure 9. This means that, for each pair, the improvement of one of the responses will produce a worsening of the other response. Therefore, finding the best compromise is necessary.

\begin{tabular}{|c|c|c|c|c|c|c|c|}
\hline $\mathrm{X}_{1}$ & $\mathrm{X}_{2}$ & $\mathrm{X}_{3}$ & $\mathrm{X}_{4}$ & $Y_{1}$ & $\mathrm{Y}_{2}$ & $\mathrm{Y}_{3}$ & $\mathrm{Y}_{4}$ \\
\hline 1 & -1 & -1 & -1 & 10.95 & 65 & 50 & 8.0 \\
\hline 0 & 0 & -1 & -1 & 11.06 & 150 & 115 & 22.9 \\
\hline-1 & 1 & -1 & -1 & 11.11 & 240 & 195 & 40.0 \\
\hline 1 & 1 & -1 & -1 & 11.09 & 90 & 67 & 13.0 \\
\hline-1 & -1 & 0 & -1 & 21.37 & 210 & 160 & 81.5 \\
\hline 1 & -1 & 1 & -1 & 31.70 & 69 & 50 & 45.0 \\
\hline-1 & 0 & 1 & -1 & 31.89 & 235 & 175 & 186.0 \\
\hline-1 & 1 & 1 & -1 & 31.90 & 250 & 190 & 196.0 \\
\hline 1 & 1 & 1 & -1 & 31.89 & 85 & 69 & 70.0 \\
\hline-1 & -1 & -1 & 0 & 13.05 & 236 & 210 & 78.0 \\
\hline 1 & 0 & -1 & 0 & 12.89 & 100 & 90 & 32.0 \\
\hline 0 & 1 & 0 & 0 & 24.61 & 170 & 160 & 145.0 \\
\hline 0 & -1 & 1 & 0 & 35.31 & 137 & 125 & 195.0 \\
\hline 0 & -1 & -1 & 1 & 15.27 & 135 & 156 & 87.6 \\
\hline-1 & 1 & -1 & 1 & 14.74 & 220 & 260 & 172.0 \\
\hline 1 & 1 & -1 & 1 & 15.54 & 98 & 116 & 72.5 \\
\hline 1 & -1 & 0 & 1 & 27.69 & 70 & 84 & 112.0 \\
\hline-1 & 0 & 0 & 1 & 28.79 & 220 & 279 & 417.0 \\
\hline-1 & -1 & 1 & 1 & 40.54 & 200 & 239 & 538.0 \\
\hline 1 & -1 & 1 & 1 & 38.75 & 75 & 82 & 170.0 \\
\hline-1 & 1 & 1 & 1 & 39.38 & 70 & 80 & 175.0 \\
\hline 1 & 1 & 1 & 1 & 39.34 & 92 & 105 & 246.0 \\
\hline
\end{tabular}

Table 2: D-Optimal Design experimental matrix and responses Y.

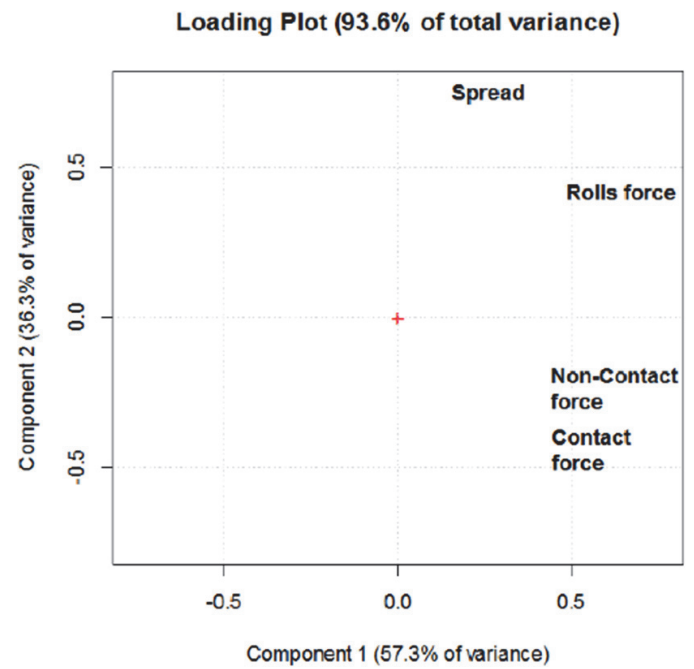

Figure 9: Loading plot of the Principal Component Analysis (PCA). 
The coefficients of the mathematical model in equation (1) are computed by Multiple Linear Regression. The mathematical model for $\mathrm{Y}_{1}$ (to be maximized) is:

$$
\begin{aligned}
\mathrm{Y}_{1} & =24.8-0.1 \mathrm{X}_{1}+0.0 \mathrm{X}_{2}+11.3 \mathrm{X}_{3}(* * *)+3.1 \mathrm{X}_{4}(* * *)+0.2 \mathrm{X}_{1} \mathrm{X}_{2}-0.1 \mathrm{X}_{1} \mathrm{X}_{3}-0.2 \mathrm{X}_{1} \mathrm{X}_{4}+ \\
& -0.0 \mathrm{X}_{2} \mathrm{X}_{3}-0.1 \mathrm{X}_{2} \mathrm{X}_{4}+0.9 \mathrm{X}_{3} \mathrm{X}_{4}(* * *)+0.1 \mathrm{X}_{1}^{2}-0.2 \mathrm{X}_{2}^{2}-0.5 \mathrm{X}_{3}^{2}-0.3 \mathrm{X}_{4}^{2}
\end{aligned}
$$

Figure 10 shows the plot of the coefficients. Two linear terms $\left(b_{3}\right.$ and $\left.b_{4}\right)$ and one interaction $\left(b_{34}\right)$ are statistically significant, with $\mathrm{b}_{3}$ being by far the most important.

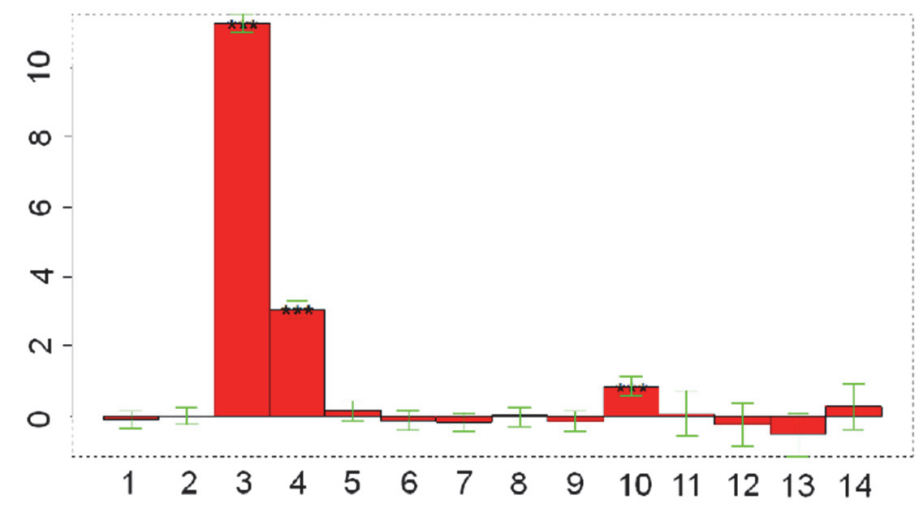

Figure 10: Plot of the coefficients of the mathematical model of the response $\mathrm{Y}_{1}$ (to be maximized).

The mathematical model for $\mathrm{Y}_{2}$ (to be maximized) is:

$$
\begin{aligned}
Y_{2} & =166-63 X_{1}(* * *)+3 X_{2}-10 X_{3}-10 X_{4}+10 X_{1} X_{2}+10 X_{1} X_{3}-13 X_{1} X_{4}-8 X_{2} X_{3}-11 X_{2} X_{4}+ \\
& -12 X_{3} X_{4}+12 X_{1}^{2}-16 X_{2}^{2}-4 X_{3}^{2}-15 X_{4}^{2}
\end{aligned}
$$

Figure 11 shows the plot of the model coefficients. Only the linear term $b_{1}$ is significant. Temperature decrease causes an increase of the response $\mathrm{Y}_{2}$, effective stress in the contact region.

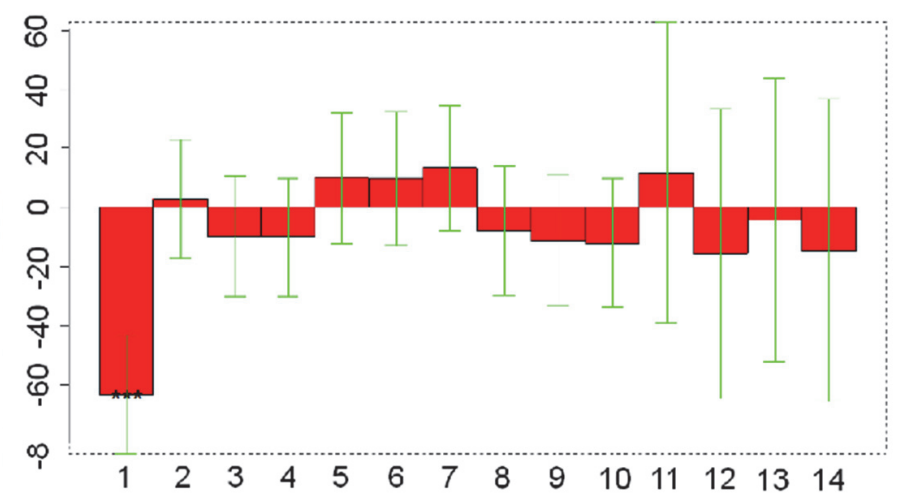

Figure 11: Plot of the coefficients of the mathematical model of the response $\mathrm{Y}_{2}$ (to be maximized).

The mathematical model for $\mathrm{Y}_{3}$ (to be minimized) is:

$$
\begin{aligned}
\mathrm{Y}_{3} & =163-59 \mathrm{X}_{1}(* * *)+3 \mathrm{X}_{2}-12 \mathrm{X}_{3}+20 \mathrm{X}_{4}+12 \mathrm{X}_{1} \mathrm{X}_{2}+12 \mathrm{X}_{1} \mathrm{X}_{3}-2 \mathrm{X}_{1} \mathrm{X}_{4}-11 \mathrm{X}_{2} \mathrm{X}_{3}-12 \mathrm{X}_{2} \mathrm{X}_{4}+ \\
& -14 \mathrm{X}_{3} \mathrm{X}_{4}+11 \mathrm{X}_{1}^{2}-22 \mathrm{X}_{2}^{2}-14 \mathrm{X}_{3}^{2}-3 \mathrm{X}_{4}^{2}
\end{aligned}
$$

Figure 12 shows the plot of the model coefficients. Only the linear term $b_{1}$ is significant. Temperature decrease causes an increase of the response $\mathrm{Y}_{3}$, effective stress in the non-contact region. 


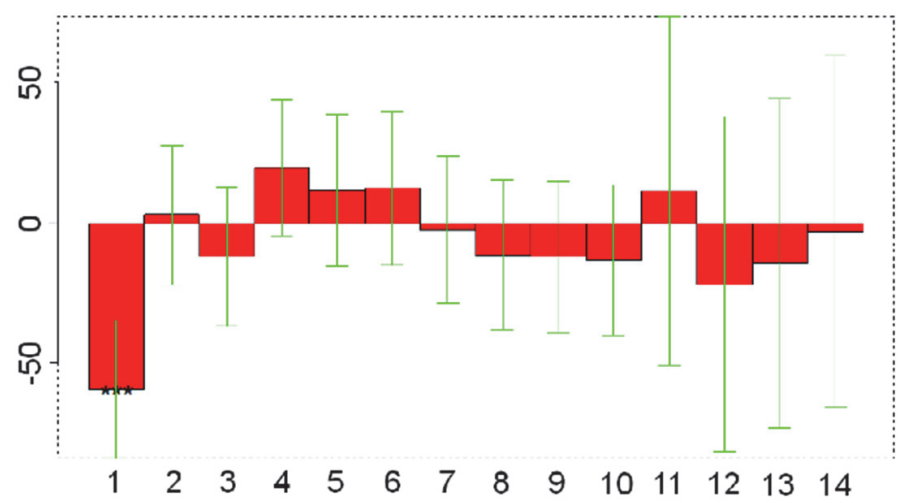

Figure 12: Plot of the coefficients of the mathematical model of the response $\mathrm{Y}_{3}$ (to be minimized).

The mathematical model for $\mathrm{Y}_{4}$ (to be minimized) is:

$$
\begin{aligned}
\mathrm{Y}_{4} & =169-57 \mathrm{X}_{1}(* * *)-6 \mathrm{X}_{2}+70 \mathrm{X}_{3}+71 \mathrm{X}_{4}+32 \mathrm{X}_{1} \mathrm{X}_{2}-14 \mathrm{X}_{1} \mathrm{X}_{3}-28 \mathrm{X}_{1} \mathrm{X}_{4}-21 \mathrm{X}_{2} \mathrm{X}_{3}-22 \mathrm{X}_{2} \mathrm{X}_{4}+ \\
& +15 \mathrm{X}_{3} \mathrm{X}_{4}+17 \mathrm{X}_{1}^{2}-49 \mathrm{X}_{2}^{2}-28 \mathrm{X}_{3}^{2}+22 \mathrm{X}_{4}^{2}
\end{aligned}
$$

Figure 13 shows the plot of the model coefficients. Three linear terms $b_{1}, b_{3}, b_{4}$ are significant. An increase of the terms $\mathrm{X}_{3}$, $\mathrm{X}_{4}$ and a decrease of the term $\mathrm{X}_{1}$ causes an increase of the response $\mathrm{Y}_{4}$, rolls reaction force.

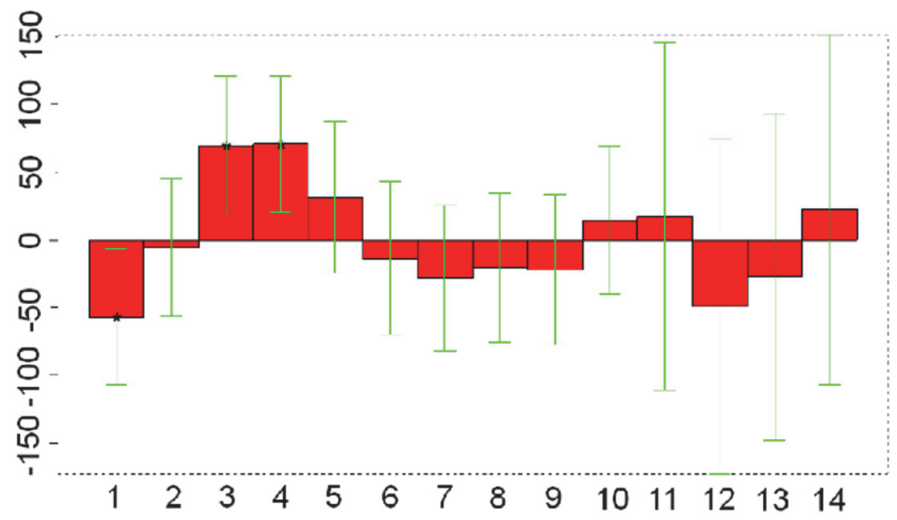

Figure 13: Plot of the coefficients of the mathematical model of the response $\mathrm{Y}_{4}$ (to be minimized).

By taking into account the four individual models, it can be seen that only the linear terms are significant, (the interaction $\mathrm{X}_{3}-\mathrm{X}_{4}$ for the response $\mathrm{Y}_{1}$, is also statistically significant, but is negligible). The variable $\mathrm{X}_{2}$ is never significant. As shown by the PCA, the pairs of responses $\mathrm{Y}_{1}-\mathrm{Y}_{4}$ and $\mathrm{Y}_{2}-\mathrm{Y}_{3}$ are correlated. Each pair requires one response to be maximized and one to be minimized, therefore a compromise has to be reached. This is possible through multicriteria decision-making methods such as the Pareto optimality approach. A definition of acceptability limits and target values for each response allows to narrow down all possible solutions combinations.

\section{MUlTiCRITERIA DECISION MAKING}

$\mathrm{P}$ areto optimality approach is applied to investigate predicted responses on a set of 729 points, obtained by the following criteria:

- temperature $\left(\mathrm{X}_{1}\right): 9$ levels in the range $800: 50: 1200{ }^{\circ} \mathrm{C}$

- rolls angular velocity $\left(\mathrm{X}_{2}\right)$ : constant (17.5 RPM)

- $\quad$ billet diameter $\left(X_{3}\right)$ : 9 levels in the range 20:5:60 mm

- billet diameter reduction $\left(\mathrm{X}_{4}\right)$ : 9 levels in the range 20:5:60\% 
Acceptability limits and target values are defined for each response. Table 3 shows the acceptability value and the target value for each response.

\begin{tabular}{ccc}
\hline Response & Acceptability & Target \\
Spread $\mathrm{Y}_{1}[\mathrm{~mm}]$ & $\geq 26$ & 27 \\
Contacts stress $\mathrm{Y}_{2}[\mathrm{MPa}]$ & 130 & 200 \\
Non-Contact stress $\mathrm{Y}_{3}[\mathrm{MPa}]$ & 200 & 130 \\
Rolls force $\mathrm{Y}_{4}[\mathrm{kN}]$ & $\leq 125$ & 80 \\
\hline
\end{tabular}

Table 3: Acceptability value and target value for each response.

317 points are non-dominated, but none of them satisfies simultaneously the acceptability requirements for all responses. Figure 14 shows the predicted values for the responses $\mathrm{Y}_{1}$ and $\mathrm{Y}_{4}$.

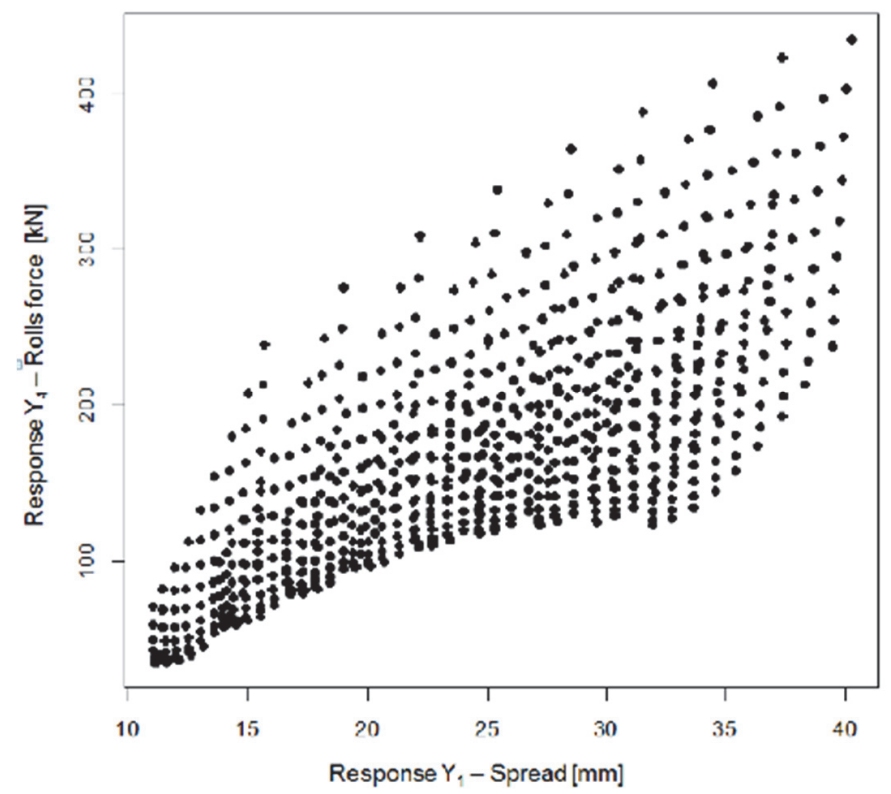

Figure 14: Spread vs. force (predicted values).

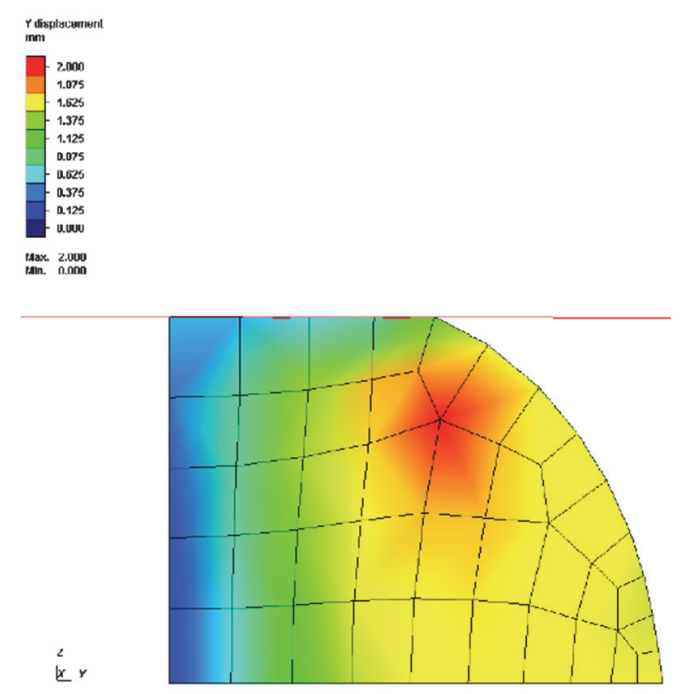

Figure 15: Simulated results for the selected conditions. 
In order to select the optimal solution, two more requirements are taken into account:

- respect a fundamental rolling process law on the bite angle:

$\mu>\tan (\alpha)$

where $\mu$ is the friction coefficient and $\alpha$ is the bite angle;

- workpiece final draught equal to $40 \mathrm{~mm}$.

This leads to the selection of the following input parameters for the $\mathrm{FE}$ simulation: temperature $1150^{\circ} \mathrm{C}$, billet diameter 50 $\mathrm{mm}$, final draught $40 \mathrm{~mm}$. The predicted responses are: $\mathrm{Y}_{1}$ (spread) $27.1 \mathrm{~mm}, \mathrm{Y}_{2}$ (contact stress) $114 \mathrm{MPa}, \mathrm{Y}_{3}$ (non-contact stress) $105 \mathrm{MPa}, \mathrm{Y}_{4}$ (rolls force) $125 \mathrm{kN}$. Figure 15 shows that the lateral displacement (spread) predicted by the DOE analysis is comparable with FE results. Responses from FE simulations are: $Y_{1}$ (spread) $26.65 \mathrm{~mm}, \mathrm{Y}_{2}$ (contact stress) 93 $\mathrm{MPa}, \mathrm{Y}_{3}$ (non-contact stress) $70 \mathrm{MPa}, \mathrm{Y}_{4}$ (rolls force) $110 \mathrm{kN}$. Only $\mathrm{Y}_{2}$ is slightly below the original acceptability target, while $Y_{1}$ and $Y_{3}$ are better than the target.

\section{CONCLUSIONS}

3 D FE models for the hot rolling process are developed using the commercial software MSC Simufact Forming. High level of accuracy in the prediction of metal flow is achieved thanks to a well-defined formulation of material model and rolling process input parameters. Based on this extensive numerical effort, further analysis is performed aimed at predicting the metal flow behavior and the optimal estimation of rolling process parameters. This objective is achieved by applying experimental design techniques to computer experiments. Flat hot rolling process simulations are performed in this analysis as a case study for this approach. Experimental design techniques are applied for parametric identification of the mathematical model coefficients for each response. Only linear terms are significant except for rolls angular velocity. Response $Y_{1}$ and $Y_{4}$ are positively correlated, as is the case for responses $Y_{2}$ and $Y_{3}$. Since each pair consists of one response to be maximized and the other to be minimized, finding the best compromise solution is required. The Pareto optimality multicriteria decision making method is employed to get a product with very good global characteristics. A good agreement between predicted and simulated values is achieved, which demonstrates high capabilities of the proposed tool for response prediction and optimization studies.

\section{REFERENCES}

[1] Wusatowski, Z. (1969). Fundamentals of Rolling. Poland: Pergamon Press.

[2] Ekelund, S. (1933). Analysis of Factors Influencing Rolling Pressure and Power Consumption in the Hot Rolling of Steel. Steel, 93, pp. 27--29.

[3] The United Steel Companies Limited. (1960). Roll Pass Design. Sheffield: The United Steel.

[4] Roberts, W. L. (1978). Hot Rolling of Steel. New York and Basel: Marcel Dekker, Inc..

[5] Bertrand, C., David, C., Chenot, J. L. and Buessler, P. (1986). Stress calculation in finite element analysis of threedimensional hot shape rolling. $2^{\text {nd }}$ Intl. Conference on Numerical Methods in Industrial Forming Process. Rotterdam: Balkema Press, pp. 207--212.

[6] Mori, K., Osakada, K. (1989). Finite-element simulation of three-dimensional deformation in shape rolling. Proc. of the $3^{\text {rd }}$ Intl. Conference on Numerical Methods in Industrial Forming Process. Fort Collins, Colorado, pp. 337--342. DOI: $10.1002 /$ nme.1620300807.

[7] Hartley, P., Pillinger, I., Sturgess, C. E. N. and Kuznetsov, S. (1990). Computer modelling of slab and section rolling. Proceedings of the $5^{\text {th }}$ Intl. Metal Rolling Conference. The Insititute of Metals, London, pp. 370--376.

[8] Galantuccia, L. M., Tricarico, L. (1999). Thermo-mechanical simulation of a rolling process with an FEM approach. Journal of Materials Processing Technology, 92, pp. 494--501. DOI:10.1016/S0924-0136(99)00242-3.

[9] Lambiase, F., Langella, A. (2009). Automated Procedure for Roll Pass Design. Journal of Materials Engineering and Performance, 18, pp. 263--272. DOI:10.1007/s11665-008-9289-2.

[10] Abhary, K., Garner, K., Kovacic, Z., Spuzic, S., Uzunovic, F. and Xing, K. (2010). A Knowledge Based Hybrid Model for Improving Manufacturing System in Rolling Mills. Key Engineering Materials, 443, pp. 3--8.

DOI: 10.4028/www.scientific.net/KEM.443.3. 
[11] Shahani, A. R., Setayeshi, S., Nodamaie, S. A., Asadi, M. A. and Rezaie, S. (2009). Prediction of influence parameters on the hot rolling process using finite element method and neural network. Journal of Materials Processing Technology, 209, pp. 1920--1935. DOI: 10.1016/j.jmatprotec.2008.04.055.

[12] Huang, B., Xing, K., Spuzic S. and Abhary K. (2010). Development of parameterized roll pass design based on a hybrid model. 2nd Intl. Conference on Mechanical and Electrical Technology, pp. 91--93. DOI: 10.1109/ICMET.2010.5598326.

[13] Spuzic, S., Izzo, A. and Abhary, K. (2006). A new method for roll pass design optimization, PhD dissertation, MAUNAfe.

[14] Lee, Y., Kim, H. J. and Hwang, S. M. (2001). Analytic model for the prediction of mean effective strain in rod rolling process. Journal of Materials Processing Technology, 114, pp. 129--138. DOI: 10.1016/S0924-0136(01)00563-5.

[15] Shinokura, T. and Takai, K. (1982). A new method for calculating spread in rod rolling. Journal of Applied Metalworking, 2(2) pp. 94--9. DOI: 10.1007/BF02834206.

[16] Lenard, J., Pietrzyk, M. and Cser L. (1999). Mathematical and Physical Simulation of the Properties of Hot Rolled Products. Amsterdam: Elsevier, pp. 59, 66, 71, 85-95, 110-11, 131-134.

[17] Kobayashi, S., Oh, S. I. and Altan, T. (1989). Metal forming and the finite-element method. Oxford University Press, pp. 41-44, 70-71, 83-86, 131-133, 291-292, 305-308, 321-322.

[18] Zienkiewicz, O. C. (1971). The Finite Element Method in Engineering Science. London: McGraw Hill.

[19] Pietrzyk, M. and Lenard, J. (1999). Thermal-Mechanical Modeling of the Flat Rolling Process. Berlin: Springer-Verlag, pp. 1-14, 98-102, 121-125, 135, 142-143.

[20] Farlow, S. J. (1993). Partial Differential Equations for Scientists and Engineers. Dover, NY, pp- 3--7, 27.

[21] Incropera, F. P. and DeWitt, D. P. (1996). Fundamentals of Heat and Mass Transfer. New York : John Wiley and Sons, $4^{\text {th }}$ edition, pp. 4, 8, 10 .

[22] Sun, W., Tieu, A. K., Li, H., Jiang, Z., Wang, G. and Liu, X. (2005). Friction in the roll bite under various hot rolling conditions. In D. Hua, L. Zhengyu D. Hongshuang (Eds.), Symposium on Advanced Structural Steels and New Rolling Technologies, Northeastern University, China.

[23] Shida, S. (1974). Effect of Carbon Content, Temperature and Strain Rate on Compressive Flow Stress of Carbon Steels. Hitachi Research Laboratory.

[24] Leardi, R. (2009). Experimental design in chemistry: A tutorial. Analytica Chimica Acta, Elsevier 652(1), pp. 161--172. DOI: 10.1016/j.aca.2009.06.015. 